\title{
Perspectivas em Psicologia Institucional - Investigação/Intervenção em Escolas Públicas da Maré
}

\author{
Perspectives in Institutional Psychology:
} an investigation and intervention in Mare's Public Schools

\section{Angela Maria \\ Dias Fernandes}

Professora Adjunta do Departamento de Psicologia da Universidade Federal da

Paraíba.Doutora em Psicologia Escolar pelo

Instituto de Psicologia da Universidade de São Paulo.

\section{Adriana Rozenowicz}

Psicóloga pelo Departamento de Psicologia da

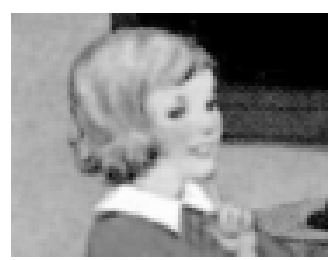

Universidade Federal Fluminense.

Elaine Cristine de Moura Freitas

Psicóloga pelo Departamento de

Psicologia da Universidade Federal Fluminense.

Joseane

Pessanha Ferreira

Psicóloga pelo Departamento de

Psicologia da Universidade Federa Fluminense.

Resumo: Este texto pretende apresentar os resultados da investigação realizada em escolas públicas da Maré/RJ. O objetivo da pesquisa era tornar visíveis os efeitos das ações de um programa social que se desenvolvia nas escolas, buscando a construção de um instrumento de avaliação de projetos sociais assentada na perspectiva de participação e coletivização. A metodologia adotada é denominada de investigação/intervenção, tendo como base ferramentas da Análise Institucional. Foi possível apreender a dinâmica das relações sociais produzidas a partir da inserção de novos atores sociais no cotidiano escolar, ganhando visibilidade as práticas instituídas e os limites das forças que se pretendem instituintes. Palavras-Chave: Psicologia Social, educação, análise institucional, metodologia de pesquisa.

Abstract: This text intends to present the results of a research done in the public schools of Maré, Rio de Janeiro. The objective of the research was to bring light to the effects of the actions of a social program that was developed in the schools, looking for the construction of an evaluation instrument for social projects based on the perspective of participation and collectivity. The methodology adopted is called investigation/ intervention, having Institutional Analysis as base tools. It was possible to apprehend the dynamics of the social relations produced by the insertion of new social actors in the school daily life, what highlighted the established practices and the limits of the forces that considered themselves instituted.

Key Words: Social Psychology, education, institutional analysis, research methodology.

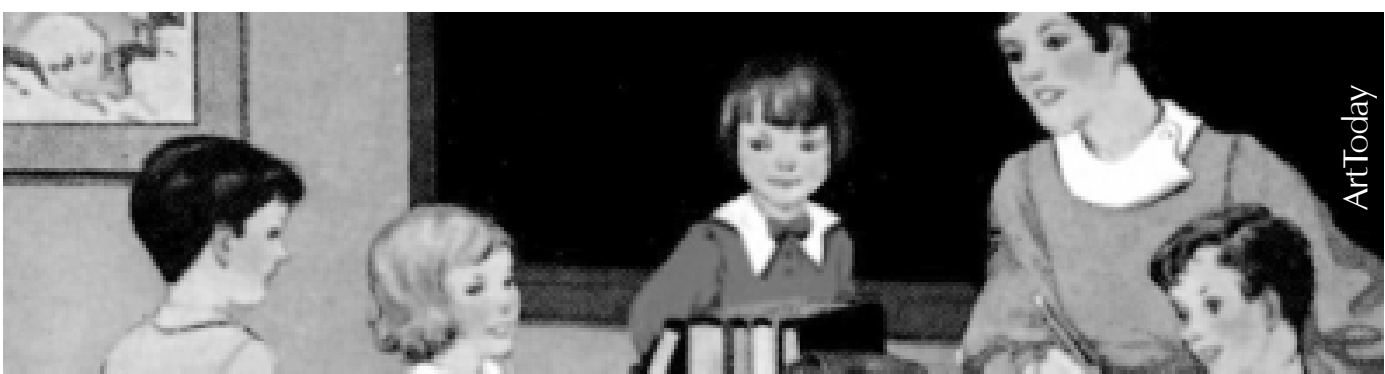

O presente trabalho propõe apresentar a pesquisaintervenção, realizada de 2000 a 2002 em escolas públicas da Maré - Rio de Janeiro. Tal pesquisa objetivou a investigação dos efeitos das ações implementadas pelo Programa de Criança na Maré e se insere em uma perspectiva de contribuir para a construção de um instrumento de avaliação de projetos sociais a partir da fala dos sujeitos envolvidos, apontando para uma linha de ação que valorize a participação e a construção da cidadania. Consiste, também, em uma possibilidade de aplicação dos estudos sobre o impacto de projetos sociais na distribuição de renda ${ }^{2}$, buscando a construção de indicadores de qualidade específicos na área da Educação que focalizem as relações sociais.

No primeiro ano, esta pesquisa teve como especificidade investigar as estratégias de ação utilizadas por professores, alunos e arte-educadores ligados ao projeto social em questão, construindo um olhar sobre as ações cotidianas que se efetivam nas escolas na busca de apreender a dinâmica das relações sociais estabelecidas. Entende-se que as ações desse programa nas escolas, dado a entrada de novos atores sociais (profissionais de arte/educação que não pertencem aos quadros da Prefeitura, estagiários e bolsistas da UFF), promovem uma intervenção na atividade pedagógica na forma como ela é prescrita. As oficinas de arte se constituem em um espaço que escapa aos mecanismos da escola em termos de conteúdo, disciplina e avaliação. $\bigcirc$ que se pretendeu foi a construção de procedimentos (entrevistas com profissionais e reuniões, questionários e outros dispositivos de abordagem) que permitissem tornar visíveis as novas relações que se constituíam a partir da parceria com esse projeto social, visando a contribuir para sua permanente avaliação e construção. A "costura" coletiva do material resgatado se inscreve, primordialmente, nessa possibilidade de intervenção sobre o cotidiano.

No segundo ano, foi realizado o mapeamento dos indicadores gerais de qualidade que pudessem servir como parâmetros para a construção de um instrumento de avaliação do programa focalizando os efeitos produzidos nos alunos, a partir da inscrição 
no projeto social, em termos de sua vinculação com a escola, com a família, com os colegas e suas projeções para o futuro. $\bigcirc$ instrumento elaborado teve o formato de questionário respondido pelo conjunto de alunos atendidos pelo projeto (cerca de seiscentos, ao final de 2001), no qual cada sujeito analisava sua própria inserção. A definição de indicadores realizada com a participação de educadores e a apropriação coletiva dos dados, pelos diversos sujeitos, é um procedimento que caracteriza essa proposta de aproximação com o campo de ação.

A presente pesquisa serviu, ainda, como objeto de reflexão sobre a atual prática da Psicologia na escola, direcionando um olhar sobre o cotidiano escolar na busca de marcas e ações que visam à produção do sujeito seriado, encerrado em si. As práticas pedagógicas também são postas em análise a partir de um processo de coletivização, apontando para uma possibilidade de desmontar mecanismos disciplinares atravessados pelo discurso hegemônico, como as relações de causalidade na explicação dos efeitos da origem social no desenvolvimento do aluno e a despotencialização e incapacidade do professor em intervir nos discursos e práticas instituídos.

\section{Entendendo o Campo de Ação da Pesquisa}

O campo de investigação privilegiado nesta pesquisa foi o Programa de Criança ${ }^{3}$, inserido em sete das treze escolas públicas da Maré, área localizada nas imediações da Av. Brasil, que reúne dezesseis favelas.

O Programa de Criança, iniciado em 1999, atende alunos do primeiro e segundo segmentos do ensino fundamental ${ }^{4}$ através de quinze oficinas que buscam criar condições de acesso a diferentes linguagens, como artes plásticas, música, teatro, dança, informática, folclore, desenho em quadrinhos etc. Essas oficinas, que se realizam nas dependências das escolas envolvidas em horários extra-classe, são ministradas por educadores que têm formação específica na área e trabalham, segundo objetivos colocados pelo programa, no sentido de contribuir para a dinamização e o aprimoramento do cotidiano escolar desses alunos, visando ao pleno exercício da cidadania e à ampliação da possibilidade de inserção social, seguindo o que afirma Paulo Freire ensinar implica compreender que a educação é uma forma de intervenção no mundo (Freire,1998, p.110).

O objetivo maior é o de contribuir para o desenvolvimento das crianças numa perspectiva mais global, construindo, através da parceria com a escola, uma proposta que possibilite um enriquecimento do espaço educativo, garantindo não só a permanência dessas crianças na escola, mas uma interferência na qualidade dessa permanência (Programa de Criança na Maré, 2001, folder).

As diferentes propostas pedagógicas que norteiam as ações dos educadores e professores da rede municipal marcam as formas de inserção desses profissionais, atualizando concepções políticas distintas na área da Educação. Nesse campo de forças, o Programa de Criança se situa em uma perspectiva instituinte, um movimento de ruptura, de desnaturalização das práticas instituídas na dinâmica escolar, sendo importante tornar visíveis quais mecanismos vão sendo acionados para capturar esses movimentos, já que o instituído e o instituinte estão em luta permanente. Entende-se que a força do programa está em sua realização enquanto oficina de arte e criação no espaço escolar oficial, gerando efeitos como o questionamento de práticas instituídas, cristalizadas. A pesquisa pretendeu investigá-las, entendendo que, nesse processo, passa a intervir e a sofrer as intervenções, no e do campo, localizando aí as possibilidades e limites enquanto metodologia.

\section{Descrevendo e Refletindo Sobre a Metodologia}

A metodologia adotada para esta pesquisa constituise em ações que produzem a um só tempo investigação e intervenção nas organizações escolares, fazendo disparar no cotidiano das escolas e atores envolvidos novas práticas e interesses. Essas estratégias situam-se na perspectiva do que, em ciências sociais, convencionou-se como Análise Institucional, corrente francesa que surgiu nas décadas de $60 / 70^{5}$. Formula a idéia de pesquisa/intervenção, questionando os sentidos cristalizados nas instituições, entendidas como um conjunto de práticas que atravessam todas as relações sociais. Propõe-se, como metodologia, a afetar os espaços de poder constituídos, de modo a permitir a promoção de novos territórios.

A pesquisa/intervenção tem como base $\mathrm{o}$ questionamento do sentido da ação e, como afirma Benevides de Barros, ocorre uma criação de campos que ao mesmo tempo criam sujeitos/objetos que se revezam como teorias e práticas (1994, p. 311).

A intervenção associa-se à construção e/ou utilização de analisadores, ou seja, de acontecimentos que produzem rupturas e análises, em um processo de desnaturalização das instituições. Na pesquisa/ intervenção, o pesquisador não é neutro , visto que a neutralidade positivista não é possível de ser conseguida. O que ocorre é a análise de implicações onde pesquisador e pesquisado, sujeito e objeto do conhecimento, constituem-se no mesmo espaço. $\mathrm{O}$ momento da pesquisa é o momento da intervenção, já que sempre se está implicado.

Lourau (1993) irá dizer que o escândalo da Análise Institucional talvez seja, justamente, o de propor a noção de implicação. Além disso, sua política traz como motriz o conceito de autogestão, que acontece
Os autores do texto constituíram a equipe das pesquisas desenvolvidas com o apoio do PIBICl CNPq: A Escola Pública e a Psicologia - Investigação Sobre as Estratégias de Acão de Diferentes Atores (2000-2001) e A Escola Pública e a Psicologia - a Produção de um Olhar Sobre as Estratégias de Ação de Diferentes Atores na Trama da Exclusão Social (2001-2002).

1 Trata-se de um projeto social que se insere nas escolas através de oficinas de arteeducação, coordenado por uma ONG atuante nessa área, que tem por norte a possibilidade de contribuir para a construção de novas estratégias da sociedade civil, intervindo nas condiçoes de escolarização e trabalho.

2 Ver o estudo do IPEA Condiçóes de Vida na Cidade do Rio de Janeiro. Rio de Janeiro: IPEA, 2001, que trabalha com o IDH (Índice do Desenvolvimento Humano) eICV (Índice de Condições de Vida).

3 o Programa de Criança é uma parceria entre uma $O N G$ e Petrobras. Algumas atividades eram desenvolvidas através de um intercâmbio com a universidade, através do Departamento de Psicologia, encerrado em março de 2002.

4 Os alunos atendidos são inscritos no programa. Nos Centros Integrados de Educação Pública são atendidas turmas de acordo com as demandas das escolas $e$ as prioridades do programa. Os alunos de $5^{a}$ a $8^{a}$ séries optam pela inscrição e se inserem nas oficinas nas quais têm interesse.

5 Destacam-se como importantes trabalhos sobre Análise Institucional os textos de Rene Lourau, como: Análise Institucional e Práticas de Pesquisa (1993) e Educação Libertária (1999), dentre outros. Ver, ainda,: Saidon, O. e Kamkhagi, V. (org.). Análise Institucional no Brasil. Rio de Janeiro: Ed. Rosa dos Tempos, 1987. 


\section{"... as dificuldades ligadas, por exemplo, ao estabelecimento de relações entre teoria e prática, à formação de equipes de \\ investigação e de trabalho, à conexão dos saberes \\ acadêmicos com os processos sociais, ò sensibilização dos professores no que se refere às formas de cultura das classes populares, às formas de colaboração entre professores $\theta$ estudantes, e muitas outras dificuldades que nos impedem} de avançar"

Varela em uma contradição total, já que a vida cotidiana se organiza no terreno da heterogestão, onde as relações de poder são demarcadas, ou como diz Lourau, nós funcionamos, em todos os lugares sob a heterogestão, ou seja, geridos por outrem. E a vivemos, geralmente, como coisa natural (p. 14).

Nesse campo de intervenção (escolas públicas da Maré e Programa de Criança), a implicação se estabelece na luta contra o fracasso escolar e os mecanismos de produção da disciplinarização, que constituem práticas de submetimento. Varela (2001) indica a necessidade de um questionamento a respeito da gênese dos saberes pedagógicos no sentido de encontrar caminhos para lidar com os obstáculos enfrentados no trabalho nas organizações escolares, apontando entre elas,

...as dificuldades ligadas, por exemplo, ao estabelecimento de relações entre teoria e prática, à formação de equipes de investigação e de trabalho, à conexão dos saberes acadêmicos com os processos sociais, à sensibilização dos professores no que se refere às formas de cultura das classes populares, às formas de colaboração entre professores e estudantes, e muitas outras dificuldades que nos impedem de avançar (Varela, 2001, p. 93).

A forma encontrada para realização da investigação/ intervenção reside na apreensão do comportamento/ dinâmica das organizações (escolas públicas da Maré), através da observação e participação no cotidiano escolar e nas oficinas, reuniões com as escolas e com os profissionais do Programa de Criança, entrevistas realizadas com os atores sociais envolvidos no processo e a coletivização dos resultados, dados e efeitos, possibilidade contida nos próprios procedimentos metodológicos.

Coletivizar significa criar um espaço onde os atores envolvidos na pesquisa possam se apropriar do material coletado/produzido, dando a esses o poder de "costurar" as falas (e os acontecimentos) da mesma maneira que "costuram" cotidianamente as estratégias de ação. Criam-se espaços de investigação/ intervenção que dão visibilidade às produções dos sujeitos envolvidos no processo de ensinoaprendizagem, caracterizando uma pesquisa singular na medida que não utiliza instrumentos de avaliação externos àquela realidade.

\section{Desenvolvimento da Pesquisa}

\section{ANO 1 - agosto de 2000 a julho de 2001}

O primeiro ano da pesquisa desenvolveu-se em duas (das sete) unidades escolares, buscando investigar o impacto produzido pelo Programa de Criança na dinâmica das escolas públicas da Maré, nas quais se constituíram-se em - aproximação com as escolas,

realização de entrevistas e preenchimento de questionários com todos os atores envolvidos no processo escolar e avaliação com os alunos inscritos no programa. Assume fundamental importância a fase de apropriação coletiva por parte dos atores, de suas próprias histórias, promovendo, através do debate, a avaliação dos aspectos da trajetória da parceria com o Programa e de suas realizações e limites enquanto equipe.

Nesse período de um ano, podem ser destacadas duas fases, sendo abordada uma unidade escolar em cada período letivo. Tanto na FASE 1 - agosto a dezembro de 2000 - quanto na FASE 2 - janeiro a julho de 2001 - foram desenvolvidos procedimentos que se circunscrevem nas três etapas descritas a seguir. A FASE 1 se deu em um CIEP (alunos de 1 ano do ciclo à 4 série), onde o programa está inserido desde sua implantação, em 1999. A primeira etapa correspondeu ao momento de aproximação com o campo, através de reuniões com a direção da escola, reuniões com a equipe do programa e participação na rotina escolar (oficinas, aulas, recreio,...) buscando apreender a dinâmica daquele espaço.

Na segunda etapa, ocorreram as entrevistas com todos os profissionais envolvidos no processo educacional, quais sejam, professores, funcionários da escola (merendeiras, secretaria, direção), educadores, totalizando trinta e dois questionários. Foi também realizada a avaliação com os alunos (cento e quarenta e sete) inseridos nas oficinas desenvolvidas nesse CIEP.

Nas entrevistas realizadas com professores e educadores, os temas abordados foram: o que pensam do Programa de Criança, quais as desvantagens e vantagens do programa, se ocorre (e como) interferência na rotina escolar. Foram obtidas como respostas mais freqüentes: 1- o programa aparece como parceiro que ajuda a complementar e diversificar as atividades, 2- sua presença é importante, pois é uma escola de horário integral, que não tem muitos recursos, 3- ajuda a promover um trabalho menos desgastante para os professores, 4- os professores vêem uma dificuldade dos educadores com os alunos (Eles não têm controle de turma, sic), 5- o programa acaba promovendo a indisciplina dos alunos.

"Eu achava melhor que todas as crianças fizessem parte, porque elas ficam olhando com olho comprido: 'Por que eles fazem parte e eu não faço?'" (profissional).

"A gente não pode criar dentro da escola uma escola diferente" (profissional).

"Eles têm oportunidade de fazer atividades que a escola não proporciona (...), com uma linguagem que a escola não tem" (profissional).

"Eles (crianças) não conseguem trabalhar na liberdade de jeito nenhum, de jeito nenhum" (profissional). 
A investigação com os alunos se desenvolveu de duas maneiras: através de uma carta endereçada ao Programa/Educadores, onde dariam suas opinióes e sugestões, e outro instrumento onde, através da confecção de desenhos e de pequenos textos, o aluno foi levado a refletir sobre si mesmo no passado, no presente e em projeções para o futuro. Essas abordagens foram feitas para entender como o aluno avalia seu pertencimento ao programa, o que pensa e o que deseja em relação a sua participação nas oficinas. As afirmações dos alunos foram feitas nas seguintes direções: 1- gostam do programa e dos educadores; 2- vêem mudanças positivas em si mesmos (mais felicidade, conheceram coisas que não sabiam).

"Era uma criança muito desatenciosa e muito triste. Sou uma criança atenciosa e alegre. Gostaria que as turmas fossem mais participativas no programa.." (criança).

"Ficava triste, não sabia fazer um texto, um desenho. Agora sou um menino feliz, eu aprendi as coisas. No futuro pode ter mais crianças para participar do programa" (criança).

O último momento dessa FASE (terceira etapa) foi o da coletivização dos resultados, realizada através de uma reunião/dinâmica com todos os profissionais abordados nesta pesquisa ${ }^{7}$. Nesse momento, os sujeitos puderam apropriar-se de suas falas e das falas dos alunos, abrindo um debate sobre essa parceria, onde surgiram temas como: 1- diferenças na relação professor/aluno e educador/aluno (autoridade $x$ autoritarismo / disciplina $x$ indisciplina), 2onipotência do programa em relação à rotina da escola, percebida pelos professores, 3 - propostas de maior articulação escola/Programa de Criança, 4promoção de cursos de capacitação de professores, a pedido da escola.

"Em alguns momentos passa a impressão de que o programa está vindo 'salvar' a escola(...) achando que vai trazer coisas que a escola não vive, que a escola não conhece e não sabe como fazer" (profissional).

"Nós temos muito pouca oportunidade de trocar com as pessoas que estão no projeto e eu penso que isso empobrece um pouco o trabalho" (profissional).

Essas falas, dentre outras, trouxeram o "incômodo" que o programa traz à rotina da escola. A questão principal, que acabou produzindo acontecimentos analisadores das práticas que atravessaram essa organização, foi o sentimento de onipotência identificado na relação entre educadores do programa e professores da escola. Os educadores, mais jovens, com formação universitária, trabalhando com o lúdico e despojados do excesso de disciplina, seriam tomados por um sentimento de superioridade, o que estaria dificultando o processo de trocas que (em tese) caracterizaria a parceria. A realização de várias reuniões subseqüentes à coletivização, com a participação de membros da pesquisa, potencializou a análise e intervenção a partir das falas resgatadas no processo de entrevista. A reação dirigida, principalmente, à coordenação do programa, promoveu uma série de reposicionamentos, fazendo modificar, inclusive, algumas prioridades e formas de trabalho do programa, como por exemplo: iniciar o atendimento a turmas de crianças cada vez mais novas, abrindo mão da prioridade para a $4 \underline{a}$ e $5 \underline{a}$ séries, construir uma composição de oficinas, oferecendo menos de quatro modalidades, com o objetivo de aumentar o quantitativo atendido, por solicitação da escola, modificar os horários e tempo de duração das oficinas como forma de resolver problemas de disciplina dos alunos. O projeto que originou a formatação do programa trazia uma

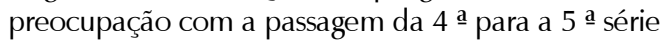
em função dos altos índices de repetência e evasão, indicando essas turmas como prioridade. $\mathrm{Na}$ articulação entre educação formal e as diversas linguagens artísticas, o projeto buscava, ainda, uma ampliação das potencialidades do aluno, incentivado à participação em, no mínimo, quatro oficinas por semestre, o que poderia produzir um engajamento maior do aluno no programa e na escola.

A FASE 2, desenvolvida em uma escola municipal onde o Programa de Criança atende alunoș do segundo segmento do ensino fundamental (de 5 a 8 série), iniciou a primeira etapa, assim como na fase 1, com aproximação desse campo de investigação/ intervenção através de entrevista com a direção da escola, onde foi apresentado todo o funcionamento da mesma e com a observação e participação na rotina escolar (oficinas, aulas, recreios, ...), em uma tentativa de apreensão da dinâmica dessa organização.

Na segunda etapa, foram elaborados e aplicados questionários semi-abertos dirigidos aos professores da escola e aos educadores e estagiários de Psicologia pertencentes ao programa, que atuavam nessa escola, com o objetivo de focalizar formas específicas de relação, uma vez que, diferentemente do CIEP, não havia propostas definitivas a priori que promovessem o estreitamento dos laços entre seus profissionais. Foram elaborados dois questionários, um para profissionais da escola e outro para os do programa. Em um universo de cinqüenta e cinco profissionais, foram respondidos cinqüenta e um questionários. A análise dos dados estatísticos mostra que $50 \%$ dos professores sabem quais de seus alunos participam do programa, enquanto $38 \%$ afirmam desconhecimento. Quando perguntados se a presença do programa interfere na rotina da escola, $41 \%$ responderam que sim, enquanto o mesmo quantitativo respondeu que não interfere. No item que indaga se o professor considera que o programa contribui para o desenvolvimento do aluno, $76 \%$ respondeu que sim, enquanto somente $21 \%$ disseram
"Ficava triste, não sabia fazer um texto, um desenho. Agora sou um menino feliz, eu aprendi as coisas. No futuro pode ter mais crianças para participar do programa"

criança 
que não. Sobre o interesse de que os alunos participem do programa, 59\% afirmou que sim, 26\% não sabem e 15\% não. Quanto aos dados qualitativos, foram apontados como vantagens do programa: socialização, melhoria de qualidade de vida, ampliação de horizontes, oferecimento de novas possibilidades, presença do aluno na escola. Como desvantagens do programa, surgiram: falta de disciplina, pouca divulgação entre os professores, pouca articulação com os professores, atendimento a um número limitado de alunos.

Em seguida, foi feita uma avaliação com os alunos (cerca de sessenta) atendidos no programa, através de duas reuniões/dinâmicas, onde foi colocado em debate o conteúdo e metodologia das oficinas e outras práticas, participação do aluno nas atividades e relação destes com a escola, entre outros temas. Um aspecto importante da história de relação com os alunos dessa escola era a existência de uma representação eleita que atuava junto à coordenação do programa, facilitando o processo de avaliação permanente e promovendo uma experiência de participação.

A última, e terceira etapa,correspondeu ao momento de coletivização dos dados que se deu por meio de duas reuniões (em função da grade de horários da escola) entre equipe de pesquisa e professores e educadores. Nesses encontros, onde os resultados da pesquisa foram encaminhados através de um documento, surgiram questões importantes como: o programa é excelente para os alunos, mas atrapalha a rotina da escola, há uma necessidade de articulação entre freqüência e rendimento dos alunos na escola e nas oficinas do programa. Foi, ainda, questionada a pertinência do funcionamento do programa nas dependências da escola.

"O programa é ótimo, todos concordam, agora por que tem que acontecer dentro da escola? É a mesma coisa que funcionar um clube e uma igreja no mesmo espaço" (profissional do corpo docente).

Essa "sacralização" do espaço escolar em oposição a uma ludicididade e possível flexibilidade no controle da disciplina, que seriam características do programa, são aspectos que se fizeram presentes na relação com a escola. A manutenção das oficinas e das demais atividades só foi possível porque houve, por parte de alguns professores, uma "aposta" na correlação positiva entre pertencimento ao programa e rendimento escolar, sendo identificada maior participação na vida escolar por parte dos alunos inscritos.

\section{Investigação de Alguns Estranhamentos}

O que surgiu de forma marcante nas duas unidades escolares foi a diferença de olhares da equipe do programa e das escolas no que se refere a alguns pontos que envolvem a relação ensinoaprendizagem, tais como: educação escolar, atividade lúdica, disciplina, autonomia dos alunos e autoridade/autoritarismo. Foi possível, também, focalizar impressões das relações de trabalho de professores e educadores, como ficou explícito nas reuniões de coletivização.

Esta pesquisa possibilitou, assim, ir além do levantamento de dados. Nos encontros para coletivização, algumas formas de trabalho cotidiano se atualizaram, causando um certo estranhamento dos sujeitos envolvidos, pois a relação dos profissionais e sua forma de trabalhar e entender a Educação foram colocadas em debate, em uma busca de criação de práticas, de desnaturalização de lugares.

Esse dispositivo precisa de manutenção constante, ou seja, outras reuniões/debates devem ocorrer para dar seqüência e suporte a tantas vozes, não sendo possível uma única intervenção dar conta de tudo, além do fato de essa força instituinte ser capturada a todo instante, naturalizando-se. Portanto, precisa ser um movimento de luta permanente.

O momento de coletivização foi importante para o surgimento de algumas questóes presentes na parceria com o programa, principalmente pelo fato de acontecer dentro do espaço escolar, gerando "bagunça" dos alunos. O que precisa ser trabalhado na relação entre educadores e professores é a relevância de, justamente, estreitar os laços do aluno com a escola, da importância da articulação entre programa/escola, entre outras questões. Os principiais temas que atravessaram as estratégias de ação dos diferentes atores foram: 1-disciplina/indisciplina dos alunos e autoridade/autoritarismo na relação pedagógica, 2 - produção de autonomia X submetimento como resultado da ação pedagógica, 3 - o lúdico na escola, exercido na perspectiva de limitação ou expansão das potencialidades/ possibilidades dos alunos.

Enfim, o que pode ser visto com os resultados obtidos é o impacto causado pela presença do programa na escola, onde por vezes surgiram alguns conflitos em função de diferentes olhares e saberes com relação ao ensino, como também um certo desconhecimento da escola em relação às propostas das oficinas e, por isso, uma necessidade de maior articulação entre os profissionais da escola e do programa. Esse momento de coletivização tornou-se, assim, uma situação analisadora onde foi possível aparecer e atualizar formas de trabalho cotidiano, onde a fala dos atores não aparece no coletivo, fica pelos corredores, gerando uma insatisfação ou mal-estar emudecido e impotente.

Assim, a problematização das questões que aprofundam o porquêe e para quê, o como das situações, 
para além da individualização e psicologização dos acontecimentos, reenvia-as a sua complexidade, que envolve as relações com a escola, com os modos de organização do processo político-pedagógico, com as formas de expressão de cada segmento, podendo levar à construção de práticas mais satisfatórias, à melhor qualidade de sua vida na escola. O exercício ético de avaliação das práticas, a eleição, a cada momento, dos problemas prioritários, apontam para as formas de atuação e estratégias mais pertinentes, afirmando relações mais solidárias (Rocha, 2001, p. 225).

A partir dos resultados obtidos nesse ano de pesquisa, houve uma solicitação, por parte dos profissionais abordados nas escolas, de avaliação dos alunos atendidos pelo programa; por outro lado, surgiu um indicativo da equipe do programa de potencializar os possíveis efeitos no processo de desenvolvimento dos alunos. Criou-se, assim, a necessidade de construir um instrumento que pudesse avaliar os efeitos da inserção do aluno no programa e pudesse contribuir para o aprimoramento das estratégias de trabalho.

\section{Ano 2 - agosto de 2001 a julho de 2002}

O segundo ano da pesquisa tomou como universo o total dos alunos (cerca de seiscentos) inscritos nas oficinas do programa em 2001, nas sete escolas, e todos os educadores e estagiários de Psicologia da UFF.

Assim como no ano anterior, a pesquisa foi dividida em duas fases - a FASE 1, de agosto a dezembro de 2001 e a FASE 2, de janeiro a julho de 2002. O objetivo desse ano da investigação/intervenção foi a construção de um instrumento de avaliação dirigido ao desempenho do aluno participante do programa.

A primeira etapa da FASE 1 possibilitou levantar e sistematizar dados relativos aos objetivos do trabalho pedagógico e os elementos utilizados para avaliação de cada atividade realizada nas oficinas do Programa de Criança. Esse levantamento foi realizado através de um questionário dirigido aos educadores que continha cinco questões sobre sua prática. O programa contava, no momento da pesquisa, com vinte e dois educadores e nove estagiários de Psicologia da UFF, que atuavam diretamente com as crianças. Desse total, foram obtidos vinte e dois questionários respondidos. Através desse levantamento, foi possível relacionar os seguintes aspectos: 1- o objetivo geral do trabalho de cada educador no programa, 2- O objetivo específico de cada oficina, 3-como é entendida a aprendizagem no contexto das oficinas, 4- quais os indicadores de aprendizagem por parte do aluno e, por fim, 5sugestões para avaliação dos efeitos da inserção dos alunos no Programa de Criança. Além da aplicação desses questionários, foram feitas observações nas oficinas no sentido de melhor contribuir para a sistematização dos dados. Também foram utilizados, como material de análise, documentos do programa que tratavam dos objetivos e metas de cada oficina.

A partir do mapeamento das respostas dadas pelos educadores, foi organizada uma reunião com a equipe do Programa de Criança, onde todos puderam se apropriar do material compilado. Foi elaborado um documento apresentado à equipe, procedendo-se a uma análise em pequenos grupos que foi debatida, nessa mesma reunião, pelo coletivo. Como resultado desse processo, chegou-se à definição dos indicadores, considerados importantes na avaliação dos efeitos das oficinas, tais como: 1 interesse na tarefa realizada, 2- percepção de alterações positivas no próprio comportamento, 3autonomia, 4- estreitamento na relação com a escola e maior implicação no processo educacional, 5contribuições das oficinas no processo de desenvolvimento do aluno, 6- contribuições nas perspectivas em relação ao futuro, 7- relação com o CEASM.

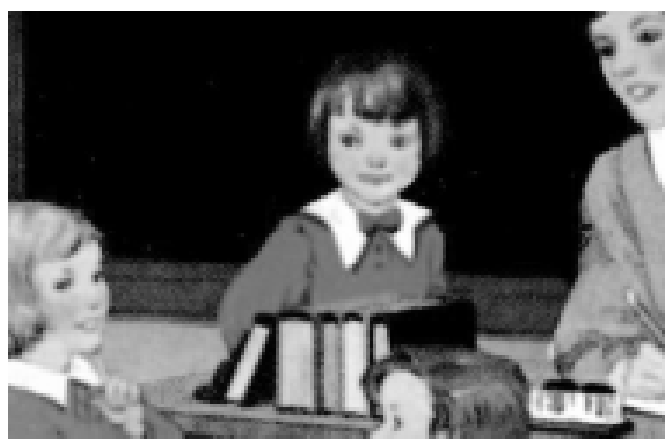

Com base nesses indicadores, foram construídos instrumentos de avaliação na forma de dois questionários. O questionário voltado para os alunos do primeiro segmento ( ${ }^{\circ}$ ano do ciclo à 4 série) investigou esses indicadores abordados em dezoito questões fechadas. $\mathrm{O}$ instrumento respondido pelos alunos do segundo segmento era composto de dezenove questões semi-abertas.

A aplicação dos dois questionários constituiu a segunda etapa dessa primeira fase da pesquisa. Foram escolhidas diferentes abordagens em função dos níveis de escolaridade, pois foi entendido que um aluno de $5^{3}$ a 8 série teria maior facilidade na leitura, escrita e compreensão do que um de CIEP, o que se confirmou no momento da aplicação. Foram abordadas as sete escolas onde o programa estava inserido, totalizando quinhentos e um questionários preenchidos. Todas as turmas responderam aos questionários, sendo que a defasagem em relação ao universo inicial, de seiscentos alunos, deveu-se a problemas de evasão de inscritos, alunos faltosos ou que não estavam presentes no momento da aplicação. Os quinhentos e um questionários respondidos correspondem a um total de $82 \%$ do 
universo. Os alunos com mais de $80 \%$ de freqüência nas oficinas responderam aos questionários.

É importante frisar que a proposta de auto-avaliação também é vista como um novo elemento na relação do aluno com o programa, identificada como uma prática pouco usual no cotidiano escolar.

A FASE 2 teve início (primeira etapa) com a compilação e análise dos dados, a partir de um levantamento estatístico que deu origem a várias tabelas e cruzamento entre as respostas.

Com relação às características dos alunos atendidos pelo programa, o maior contingente $(85,63 \%)$ está cursando o primeiro segmento do ensino fundamental. A maioria dos alunos inscritos, ou $71,66 \%$ do total, iniciaram sua participação no ano de 2001. Dos inscritos no ano de 1999, somente $7,98 \%$ continuavam inscritos ao final de 2001. Os ingressos no ano de 2000 totalizam 17,56\% do grupo de sujeitos abordados pelo questionário.

Os indicadores apontam na direção de uma investigação da qualidade do projeto educacional do programa, que estaria investindo na produção de um sujeito autônomo e compossibilidade crítica e de intervenção na sociedade.
Investigando o comportamento dos alunos, a maioria destes percebe que, desde que entrou para o programa, pode fazer coisas que não fazia antes $(38,12 \%)$. Esse dado é mais relevante, chegando a $42,5 \%$, se forem tomados somente os alunos que ingressaram no programa no 2 semestre de 1999 , quando este se inicia. Isto nos permite pensar que o ingresso no programa, pela diversidade apresentada a eles por meio das oficinas em que se inserem, modifica o modo como esses alunos se percebem frente às novas possibilidades de atuação, o que seria, também, influenciado pelo tempo de participação no programa.

No que se refere ao processo de ensino aprendizagem, a grande maioria dos alunos $(86,23 \%)$ acusa a ocorrência de melhorias em relação à participação nas aulas. Na relação com os colegas da escola, 56,68\% dizem ter mudado para melhor. A relação com os professores foi considerada melhor por $64,67 \%$ do total dos alunos que respondeu aos questionários. A escola passa a ser vista como mais interessante por $68,86 \%$, e a maioria $(77,24 \%)$ também diz ter maior facilidade para expor suas opiniões. Com relação ao aprendizado nas aulas, $89,02 \%$ dos inscritos no programa acusam melhorias. Observa-se, também, que $82,03 \%$ dos alunos dizem que o que aprendem nas oficinas contribui para sua vida fora da escola, e $81,44 \%$ dizem ter acontecido modificações nos planos para o futuro. Essas mudanças de comportamento são observadas pelos familiares desses alunos em mais da metade dos casos $(66,66 \%)$.

Pode-se concluir que o questionário construído conseguiu investigar a influência desse programa junto aos alunos nele inscritos, constituindo-se como um interessante instrumento de avaliação desse projeto social. Os indicadores apontam na direção de uma investigação da qualidade do projeto educacional do programa, que estaria investindo na produção de um sujeito autônomo e com possibilidade crítica e de intervenção na sociedade. A análise dos dados indica alguns caminhos para a continuidade da investigação, chamando a atenção a maior concentração de respostas positivas no grupo de alunos inscritos em 1999 e 2000 do que naqueles que iniciaram em 2001, dentre outros aspectos que podem suscitar estranhamentos.

Em uma segunda etapa, esses dados foram objeto de um novo olhar que pretendeu maior compreensão sobre os indicadores utilizados para avaliação do projeto social em questão, tomando como elementos os produtos da investigação teórica realizada ao longo da pesquisa. Foram priorizados temas relativos à política educacional e questões atuais da Educação associados às análises das formas específicas de avanço do neoliberalismo no Brasil e sua repercussão no campo da educação, pesquisas oficiais que trabalham com indicadores de desenvolvimento humano e condições de vida (IDH e ICV), como o documento do IPEA, análises sobre textos que questionam a utilização de indicadores de qualidade (Salama e Destremau, 1999) e, por fim, abordagens no campo da Psicologia que contribuíram para o fortalecimento dos princípios metodológicos não só da investigação/intervenção como da inserção da Psicologia na escola. Esse processo permitiu uma ampliação na possibilidade de análise que o material de pesquisa sugeria.

A terceira etapa refere-se ao encaminhamento do resultado da pesquisa à equipe do programa. Essa etapa sofreu uma alteração em função das contingências de trabalho daquela equipe. Houve uma mudança na coordenação do programa que resultou no encerramento do intercâmbio com a $\mathrm{UFF}^{8}$. A pretendida coletivização no processo de apropriação dos resultados finais escapou do âmbito dessa pesquisa, podendo ser realizada ou não de acordo com a correlação de forças que no momento de recebimento do material estiver movimentando o projeto social. Nesse caso, esta pesquisa se encerra, ficando a continuidade da intervenção a cargo do relatório que passa a ser compreendido como um importante "ator" nessa trama.

\section{Algumas Reflexões Sobre uma Pesquisa que Produz Efeitos}

Nesse item, cabe investigar os limites e possibilidades de um aporte metodológico que não pretende "mensurar" ou simplesmente "conhecer" um objeto. A perspectiva da intervenção instaura um campo de investigação sujeito a incorporação dos efeitos que a pesquisa produz. 
No caso do trabalho aqui relatado, podem ser destacados alguns desses efeitos. No primeiro ano, quando o foco estava colocado sobre as relações sociais que marcavam o cotidiano das escolas a partir da entrada do Programa de Criança, o que ganhou visibilidade foram os mecanismos disciplinares que as escolas acionavam e as formas como eram justificados. A disciplina $X$ indisciplina, autoridade $X$ autoritarismo, o lúdico $X$ acadêmico e autonomia $X$ submetimento foram os temas que se fizeram presentes na análise dos efeitos daquele projeto social nas escolas. Ganhou, também, visibilidade o processo de institucionalização, onde práticas instituídas e forças instituintes mostraram sua dinâmica.

O segundo ano da pesquisa foi marcado pela definição dos indicadores de qualidade e dos instrumentos de avaliação (dois questionários respondidos pelos alunos) alicerçados na perspectiva, afirmada pelos educadores que participaram da investigação, de produção do conhecimento baseado na autonomia e criatividade e pela possibilidade de mudança nas relações entre os atores sociais. Essa perspectiva filosófica deve ser constantemente analisada tomando como referência o conjunto de práticas compreendidas como o resultado de um processo constante de institucionalização, de captura, pelas forças instituídas, daquilo que se pretende instituinte. Isso significa dizer que os indicadores aqui construídos podem ser específicos de determinada conjuntura e que sua manutenção depende da potência para manter a filosofia da ação pedagógica que serviu de base para a sua construção. Por esse caráter, a definição dos indicadores prevê análise da implicação com a proposta e com as práticas pedagógicas por parte de todos os atores sociais.

Aqui, ressalta-se a importância da metodologia da pesquisa que, constituindo um campo de intervenção, incorpora os efeitos como capazes de rupturas. $\mathrm{O}$ encerramento do intercâmbio com a universidade colocou um limite concreto, definindo um novo enquadre na devolução dos resultados e na pretendida coletivização. Isso pode significar que a pesquisa produziu um efeito sobre si mesma, demarcando limites e possibilidades não somente da metodologia adotada, mas também do próprio Programa de Criança em se constituir um campo de investigação/intervenção.

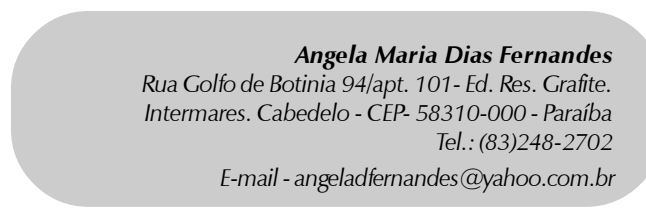

Recebido 16/10/02 Aprovado 02/01/04

BENEVIDES DE BARROS, Regina. Grupo-a Afirmação de um Simulacro. Tese de Doutorado, São Paulo: PUC/SP, 1994

CENTRO DEESTUDOSEAÇÕESSOLIDÁRIAS DAMARÉ(folder) Programa de Criança na Maré. Rio de Janeiro: CEASM, 2001.

FREIRE, Paulo. Pedagogia da autonomia-saberes necessários à prática educativa. Rio de Janeiro: Ed. Paz e Terra, 1998.

INSTITUTO DE PESQUISA ECONÔMICAAPLICADA(IPEA). Condições de Vida na Cidade do Rio de Janeiro. Rio de Janeiro: IPEA, 2001.
IOURAU, René. Análise Institucional e Práticas de Pesquisa. Rio de Janeiro: UERJ, 1993.

ROCHA, Marisa Lopes da. Educação e Saúde: Coletivização das Açõese Gestão Participativa. In MACIEL, Ira. (org.) Psicologia e Educação - Novos Caminhos. Rio de Janeiro: Ciência e Profissão, 2001.

VARELA, Júlia. O Estatuto do Saber Pedagógico. In O Sujeito da Educação: Estudos Foucaultianos. Petrópolis: Ed. Vozes, 2000.
Referências 